inches. The estimate unit is the working circle which usually corresponds with a Forest Ranger District and averages over one million acres in area. For each working circle, separate estimates are being made for Crown lands and for private and licensed lands where such occur. During the latter stages of the inventory, a staff of about 20 is being employed on mapping and compilation. Work has been greatly expedited by the use of a battery of calculating machines and adding machines.

The whole Forest Zone has been divided into eight Forest Sections and the intention is to publish a separate bulletin for each, giving tables of area and volume and other pertinent information as to growing conditions.

The object of the Forest Inventory is to give a reasonably accurate estimate of the productive forest area, and of the present timber volumes and age classes by districts. This information will be available to anyone interested in starting new forest industries in any part of the Province, and will be of great assistance in the planning of such industries.

The Forest Inventory is considered to be a necessary first step in scientific forest development. Further steps are: improved protection from fire, insects and disease; advancement in cutting practices; better guarantees of regeneration after cutting; and extension of working plans covering sustained yield by districts. It is expected that further assistance from the Federal Government will be made available along these lines, and negotiations to this effect are already taking place between the Provincial and Federal Governments.

Contributed by C. B. GIIL

\title{
CONGRESS OF ENTOMOLOGY
}

The Tenth International Congress of Entomology will be held in Montreal on August 17-25, 1956. Following the Congress a number of excursions to places of entomological interest will be arranged.

All those hoping to attend the Congress and wishing to obtain further information should communicate as soon as possible with the Secretary, Mr. J. A. Downes, Division of Entomology, Science Service Building, Ottawa, Ontario, Canada.

\section{TECHNICAL NOTE \\ Rubber-Base Paint For Tree Marking by J. M. Jarvis}

Marking trees is usually a messy job, and because the lead paints in general use are difficult to wash from the hands, face, and clothing, the work is greatly disliked by most foresters. Special tree-marking paints which do not require mixing, and paints in stick form, may be obtained but these are not readily available through normal retail outlets.

In October 1954, the author began a test to determine the usefulness of rubber-base paints for tree marking. Some 705 trees on an experimental area were marked with lead paint; another 223 trees on an adjacent area were ${ }^{1}$ Research Forester, Forestry Branch, Department of Northern Affairs and National Resources, Ottawa. 